\title{
GSM and GPS Based Garbage and Waste Collection Bin Overflow Management System for Kitwe City Council
}

\author{
Ngosa Willie ${ }^{1}$, Kapata Lucy $^{2}$, Katawa Shadrick ${ }^{3}$, Phiri David Victor ${ }^{4}$, Sinonge John ${ }^{5}$ \\ Electrical Engineering Department \\ The Copperbelt University \\ P.O BOX 21692 \\ Kitwe, Zambia
}

\begin{abstract}
The Kitwe City Council in Zambia has had many challenges when it comes to garbage collection in markets and other public places. Garbage bins remain uncollected for long periods of time putting the lives of marketeers at risk in an event that there is Cholera outbreak especially during the rainy season. This happens because the Kitwe City Council does not have a system that monitors the garbage levels and notifies the Central Office. In order to avoid such a situation, this project proposes the design and implementation of a GPS and GSM Based Garbage and Waste Collection Bin Overflow Management System using GPS and GSM technology in providing real time information on the status of the garbage bins, i.e. when they are full so that appropriate action can be carried out. The system notifies the person (Truck Driver) in charge of garbage collection by sending a short message (sms) and telling them where the full bin is exactly located. Again after sometime the system notifies the Central Office that the message has been sent to the Driver. This development will ultimately save a lot of time especially when the council does not have to go and check the level of garbage in the bin. Besides, it will timely prevent the overflow of garbage due to the fact that garbage will be collected on time. That is, the council will collect garbage only when it is time to do so rather than routine where even half-full bins are collected.
\end{abstract}

Keywords- HC-SR04 Ultrasonic Sensor; GSM Module; Arduino Mega 2560; GPS Modem; Bin Overflow Management.

\section{INTRODUCTION}

The Global Positioning System (GPS) consist of a network of 24 active satellites (and 8 spares) located nearly 20,000 kilometers above the Earth's surface.The satellites circle the globe once every 12 hours to provide worldwide position, time and velocity information[1][2]. The Global System for Mobile communication (GSM)is a globally accepted standard for digital cellular communication. Whereas the GPS makes it possible to precisely identify locations on the Earth by measuring the distance from the satellites, the GSM uses narrowband time division multiple access (TDMA) for providing voice and text based services over mobile phone networks[3]

Thus, the GSM and GPS Based Garbage and Waste Collection Bins Overflow Management System is a technology which uses GSM and GPS operating through satellites and ground based stations to monitor the level of garbage in the waste collection bin. Monitoring is achieved by the use of a level sensor which activates the GSM module when the level of garbage in the bin reaches the threshold level. In this case, the GSM module notifies the person in charge of collection via a short message service (sms). At the same time the GPS receiver provides the precise location of that bin ready to be collected. Thus, this project provides an efficient way of garbage collection for the City Council.

This research is important as it will help the Council to collect garbage on time and prevent overflow of garbage. Researchers will understand how control systems work and at large it will enhance sanitation in the country as a whole. However, this project covers the aspect of just being able to monitor the level of garbage in the bins and give the exact location of the bins at a particular instant.

This project makes use of an Arduino Mega 2560, SIM900A GSM module, GPS modem, HC-SR04 Ultrasonic sensor, and the 9V DC power supply to achieve the objectives

\section{LITERATURE REVIEW}

\section{A. Waste Bin Monitoring System Using Integrated Technologies.}

This project uses Zig Bee and GSM technology. The sensors are placed in the common garbage bins placed at the public places. When the garbage reaches the level of the sensor the ARM 7 Controller gives an indication to the driver of garbage collection truck as to which garbage bin is full and needs urgent attention. This is done by sending SMS using GSM technology. Figure 1 shows the how this is implemented [4]

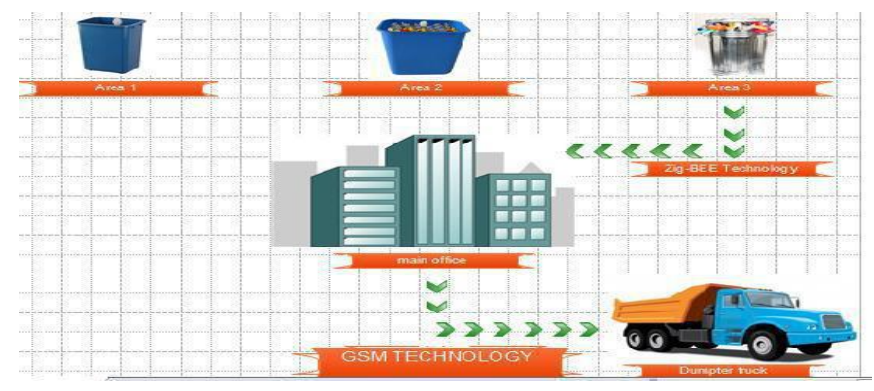

Figure 1.Implementation of Solid Waste Management [4]. 


\section{B. Dust Bin Monitoring System}

Whenever the garbage is full information can be send to the concerned authority to clean the bin. GSM is used in the project as a communication back bone for the whole system for various reasons like low cost, easy to implement and less signal deterioration. This project uses the Infrared (IR) module, GSM Modem, the PIC Microcontroller and Liquid Crystal Display (LCD) as shown by the block diagram in figure 2 .

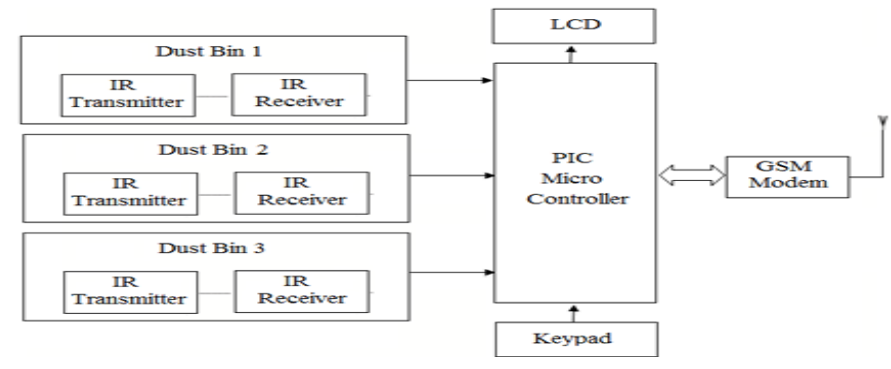

Figure 2.Block diagram for dust bin monitoring system [5].

\section{A Novel Approach to Garbage Management Using Internet of Things for Smart Cities}

Without a smart waste management system, any smart city is incomplete. In the proposed system, the level of waste material in the garbage bin has been detected with the help of ultrasonic sensor and it will continuously communicate to the authorized control room through GSM module. Microcontroller is used to interface the sensor system with GSM system. A GUI is also developed to supervise the desired formation related to the garbage for various selected locations. This system will help to assure a healthy hygienic environment.Arduino Uno board along with GSM module is used for wireless communication with control room and the cleaner [6]

This project uses Arduino Uno board, ultrasonic sensor, MATLAB based GUI. The block diagram of the project is shown in figure 3.

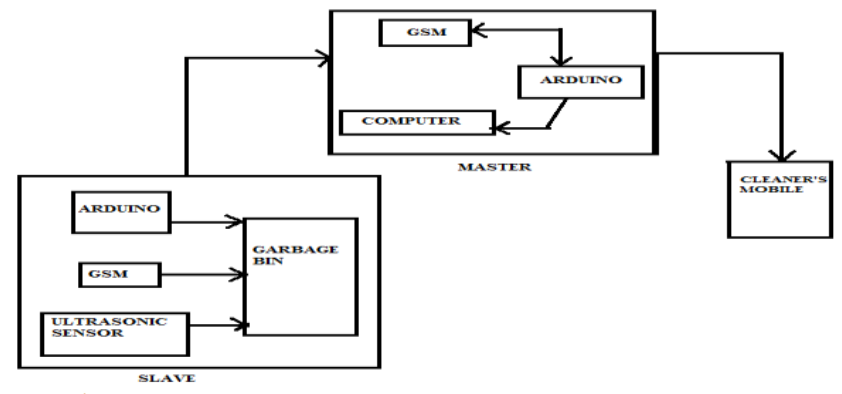

Figure 3. Block diagram of smart garbage management system [6]

The slave unit is placed in the garbage bin and the master unit is placed at the control room. Once the level of garbage reaches the specified threshold values, the ultrasonic sensor gives an indication to Arduino Uno Board and through GSM; SMS will be sent to control room informing the cleaner that the bin is full. When the SMS is received in the master unit at the control room, it will indicate on GUI the percentage of level [6]. Also the status of each bin is sent to the control room every passing hour.

\section{PROPOSED GSM AND GPS BASED GARBAGE AND} WASTE COLLECTION BIN OVERFLOW MANAGEMENT.

This section covers the details of the components used in this projectand their correspondingjustifications.

\section{A. Components Used}

This project makes use of the following materials to accomplishthe objectives: Arduino Mega2560, HC-SR04 Ultrasonic sensor, SIM900 GSM Module, and GPS Modem. The specifications and justifications all modules enlisted are explained in detail hereunder.

Arduino Mega 2560: This is heart of the entire project. It is microcontroller board based on the ATmega 2560It has 54 digital input/output pins (of which 14 can be used as PWM outputs), 16 analog inputs, 4 UARTs (hardware serial ports), a $16 \mathrm{MHz}$ crystal oscillator, a USB connection, a power jack, an ICSP header, and a reset button. It contains everything needed to support the microcontroller; it is simply connected to a computer with a USB cable or powered with an AC-to-DC adapter or battery to get started [7]. Figure 4 shows the Arduino mega 2560.

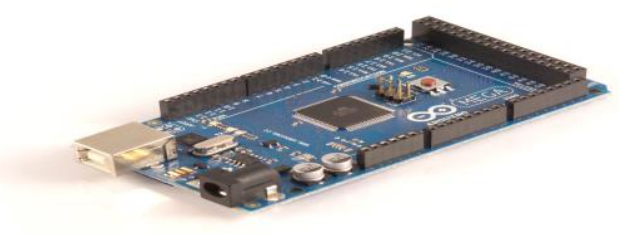

Figure 4. The Arduino mega 2560[8]

Figure 5 shows the Arduino Mega 2560 pin sections specified by colours.

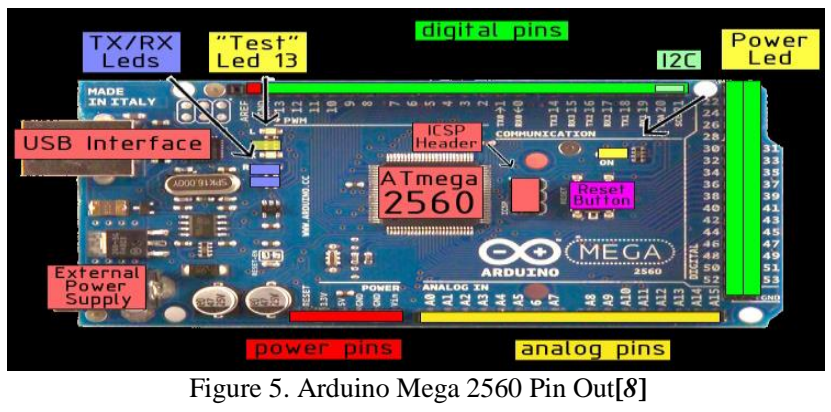

Table 1 below shows the summary of specifications for Arduino Mega 2560.

Table 1: Specifications Arduino Mega 2560[8]

\begin{tabular}{|l|l|}
\hline Microcontroller & ATmega2560 \\
\hline Operating Voltage & $5 \mathrm{~V}$ \\
\hline Input Voltage (recommended) & $7-12 \mathrm{~V}$ \\
\hline Input Voltage (limits) & $6-20 \mathrm{~V}$ \\
\hline Digital I/O Pins & 54 (of which 14 provide PWM output) \\
\hline Analog Input Pins & 16 \\
\hline DC Current per I/O Pin & $40 \mathrm{~mA}$ \\
\hline DC Current for 3.3V Pin & $50 \mathrm{~mA}$ \\
\hline Flash Memory & $256 \mathrm{~KB}$ of which $8 \mathrm{~KB}$ used by bootloader \\
\hline SRAM & $8 \mathrm{~KB}$ \\
\hline EEPROM & $4 \mathrm{~KB}$ \\
\hline Clock Speed & $16 \mathrm{MHz}$ \\
\hline
\end{tabular}


Reference [8] gives the pin description of the Arduino Mega 2560.

HC-SR04 Ultrasonic Sensor: This is used to determine the distance to an object.. It offers excellent non-contact range detection with high accuracy and stable readings in an easy-touse package from $2 \mathrm{~cm}$ to $400 \mathrm{~cm}$. It operation is not affected by sunlight or black material.It comes complete with ultrasonic transmitter and receiver module[9].The specifications of the HC-SR04 Ultrasonic sensor are given in table 2.

Table 2: HC-SR04 Specifications [9]

\begin{tabular}{|l|l|l|l|l|}
\hline Parameter & Min & Tvpical & Max & Unit \\
\hline Operating Voltage & 4.50 & 5.0 & 5.5 & $\mathrm{~V}$ \\
\hline Ouiescent Current & 1.5 & 2 & 2.5 & $\mathrm{~mA}$ \\
\hline Working Current & 10 & 15 & 20 & $\mathrm{~mA}$ \\
\hline Ultrasonic Frequency & - & 40 & - & $\mathrm{kHz}$ \\
\hline
\end{tabular}

The HC-SR04 has four direct pins namely the input voltage pin (Vcc), trigger pin (TRIG), the echo pin (ECHO), and the ground pin (GND). Figure 6 depicts the HC-SR04 Ultrasonic Sensor.

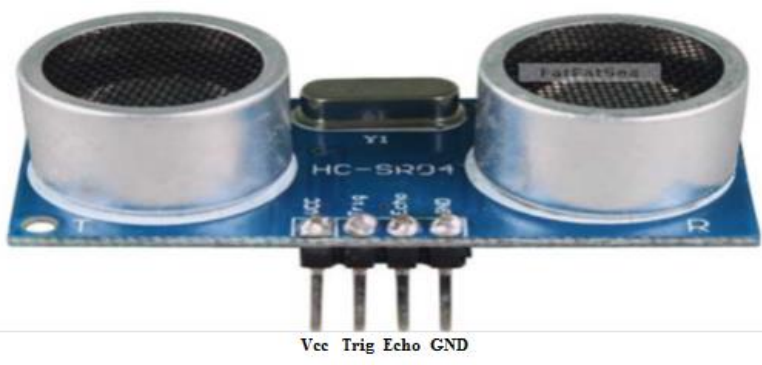

Figure 6 HC-SR04 Ultrasonic sensor [9]

The operating principle of the HC-SR04 Ultrasonic sensor is explained using figure 7.

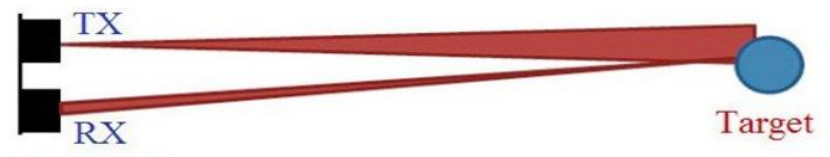

HC-SR04

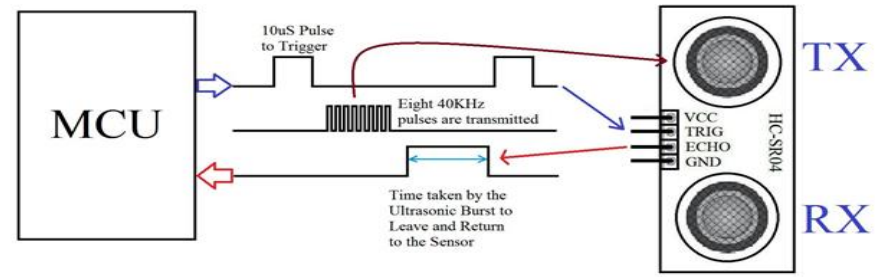

Figure 7 Operating principle and timing diagram of the ultrasonic sensor [10].

To start measurement, Trig of HC-SR04 mustreceive a pulse of high $(5 \mathrm{~V})$ for at least $10 \mathrm{us}$, this initiates the sensor to transmit out 8 cycle of ultrasonic burst at $40 \mathrm{kHz}$ and wait for the reflected ultrasonic burst. When the sensor detected ultrasonic from receiver, it will set the Echo pin to high $(5 \mathrm{~V})$ and delay for a period (width) which proportion to distance.
To obtain the distance, the width (Ton) of Echo pin is measured and the speed of sound, which is 340 meters per second is utilised[9].

With the speed, $\mathrm{S}$, of sound in air 340 meters per second, and the measured time $\mathrm{t}$ in seconds, the distance $\mathrm{D}$ in meters can be calculated as

$$
D=\frac{S \times t}{2}=\frac{340 \times t}{2}
$$

In order to read the measurement, the HC-SR04 is interfaced with any display screen through a microcontroller. Figure 8 illustrates how distance measured by the sensor can be displayed on the LCD screen using Arduino UNO board.

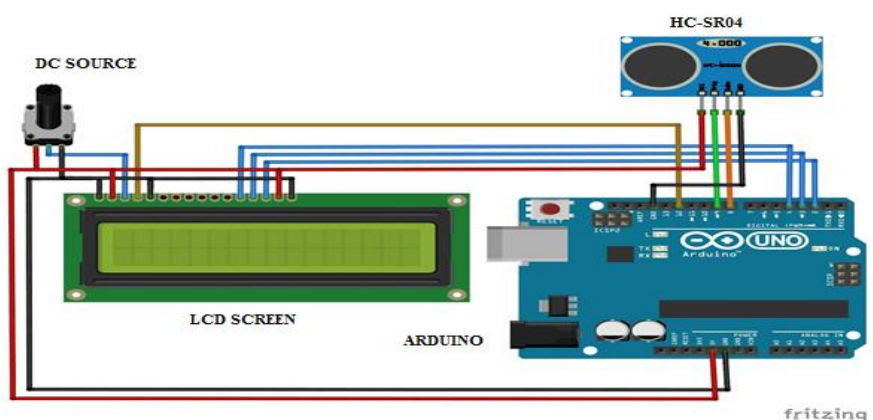

Figure 8: Interfacing HC-SR04 with LCD using Arduino UNO [11]

SIM900A GSM Module:The GSM Module is used to send or receive messages and make or receive calls just like a mobile phone by using a SIM card by a network provider.To be connected to a cellular network, the shield requires a SIM card provided by a network provider[12]. Figure 9 shows the SIM900A GSM Module.
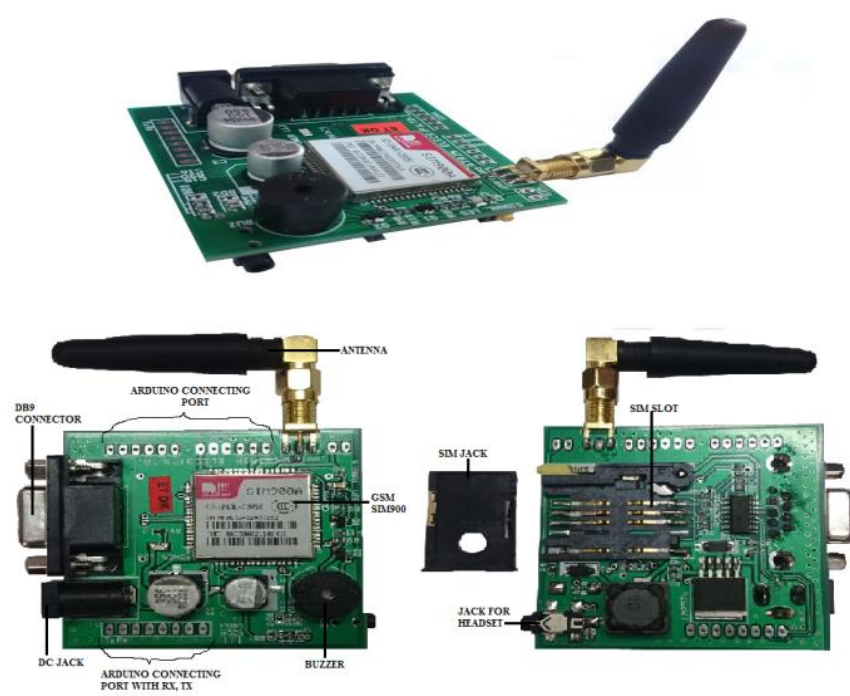

Figure 9 Parts of SIM900A GSM Module [12]

When the modem is powered upby external power supply, the Network LED will blink every second. After the Modem registers in the network (it takes 10-60 seconds), this LED will blink in step of 3 seconds at slow rate. At this stage we can start using the modem for our application. This shows that the modem is registered with the network [12]. The GSM Module is connected to Arduino such that RX, TX of the module is connected to the TX, RX of the Arduino Mega. Then required program is burnt in The Arduino Mega using the Arduino software. 
The GPS Modem: A GPS receiver tracks and uses multiple satellites for fast, accurate positioning and velocity estimates. GPS Modules uses real-time WAAS corrections yielding accuracy of less than 3 metres [13] That is, a GPS Receiver is receives GPS signals for the purpose of determining the device's current location on Earth. Figure 10 shows the GPS Modem.

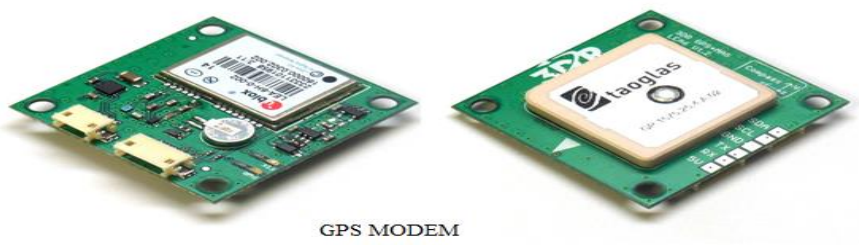

Figure 10 GPS Modem [14].

To display the current position of the receiver, the GPS Modem is interfaced with the Arduino such that pin TX of the GPS receiver is connected to pin RX of the Arduino, and pin $\mathrm{RX}$ of the receiver to pin TX of the Arduino as shown in figure 11 .

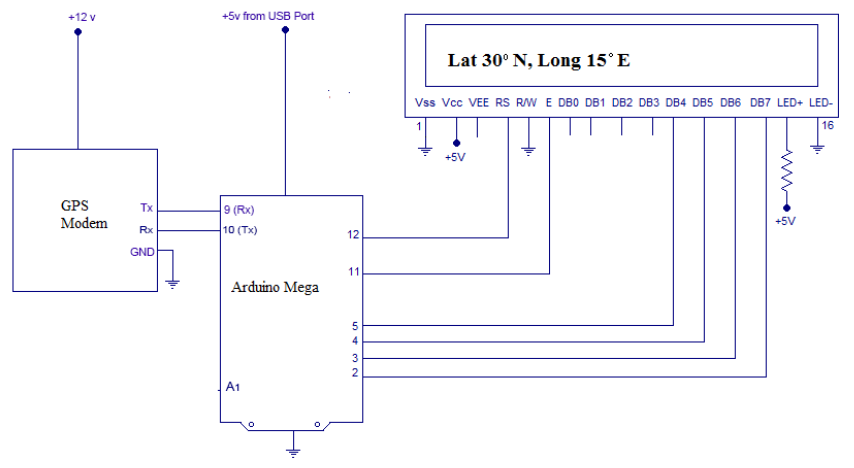

Figure 11 Interfacing the GPS Modem with Arduino. Source: Author

\section{B. Component Justifications}

The following are some of the reasons for the choice of components used in this project:

- Arduino Mega 2560: The Arduino Mega 2560 has enough memory to accommodate the project program code. Basically, it contains everything needed to support a microcontroller; it can just be connected to a DC power source to get started. Each of 54 digital pins can be used as an output or input.The GPS and GSM Modules can be connected directly to the Arduino Mega (no need for the MAX232 Interface). Compared with other microcontrollers, it is easy to program the Arduino Mega 2560 using the Arduino Software especially for beginners. Furthermore, the Mega 2560 has a resettable polyfuse that protects computer's USB from shorts and over currents[7]
- HC-SR04 Ultrasonic Sensor: Ultrasonic sensors have been the right choice for the following types of obstacles: cardboards, paper sheets, plastics, wood, rubber, and tile[15]. Most of the generated wastes in Chisokone are of these types. The HC-SR04 gives the accurate distance measurement using the transmit-echo operation. In the case of Infra-Red (IR) sensors, if any waste sticks on the surface of the sensor, the sensor may send a signal even if the bin is not up to the threshold level.Because this project is based on the overflow management, the weight sensors may give an indication for the bin to be picked even if the threshold level has not been reached, or may not indicate anything even when an overflow of garbage but its threshold weight has not been reached. Therefore, the Ultrasonic sensor best suits this project to give the accurate information about the bins in order to avoid overflow of garbage.

- SIM900A GSM Module: The following features of SIM900A GSM Module attract its use in this project; it presents an ultra-compact and reliable wireless module. The SIM900A is a complete Dual-band GSM/GPRS module which allows users to benefit from small dimensions and cost-effective solutions. The SIM900A delivers GSM/GPRS 900/1800MHz performance for voice, SMS, Data, and Fax in a small form factor and with low power consumption its power consumption being $1.5 \mathrm{~mA}$ (sleep mode). With a tiny configuration of $24 \mathrm{~mm} \times 24 \mathrm{~mm} \times 3 \mathrm{~mm}$, SIM900A can fit almost all the space requirements in applications, especially for slim and compact demand of design. In addition, the operation temperature ranges from $-40{ }^{\circ} \mathrm{C}$ to +85 ${ }^{\mathrm{O}} \mathrm{C}[15]$.

- GPS Modem: The GPS Modem is specifically included in this project so as to give the precise location of the bins being monitored. The GPS receiver is capable of retrieving from the GPS system location and time information in all weather conditions, anywhere on or near the Earth as long as there is an unobstructed line of sight to four or more GPS satellites.

\section{PROPOSED SYSTEM DESIGN}

The proposed system integrates the following components: Arduino Mega 2560, HC-SR04 Ultrasonic Sensor, GPS Modem, SIM900A GSM Module and the 9 V DC supply.

\section{A. Working Principle}

The ultrasonic sensor, placed on top of the bin and triggered by the Arduino Mega 2560, measures the level of garbage in the bin. When the level of garbage in the bin reaches the threshold value, the sensor sends the signal to the Arduino Mega which in turn activates the GSM Module and the GPS Modem. The GPS Modem captures the location of the bin which sent to the GSM Module. Then the GSM Module combines the message with the captured location (coordinates) of the bin. This combination is now sent to the Truck Driver (garbage collector) as a notification. Besides, another notification is sent to the Central Office to inform them that the collector has been notified. Figure 12 shows the block diagram of the entire system. 


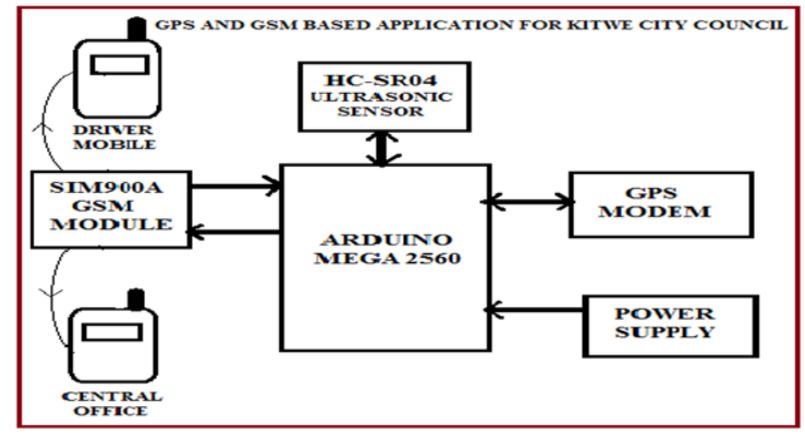

Figure 12 Block diagram of GPS and GSM based system. Source: Author

\section{B. Signal Flow Graph}

The working principle depicted by the block diagram in figure 12 can be summarized by the signal flow graph in figure 13 below.

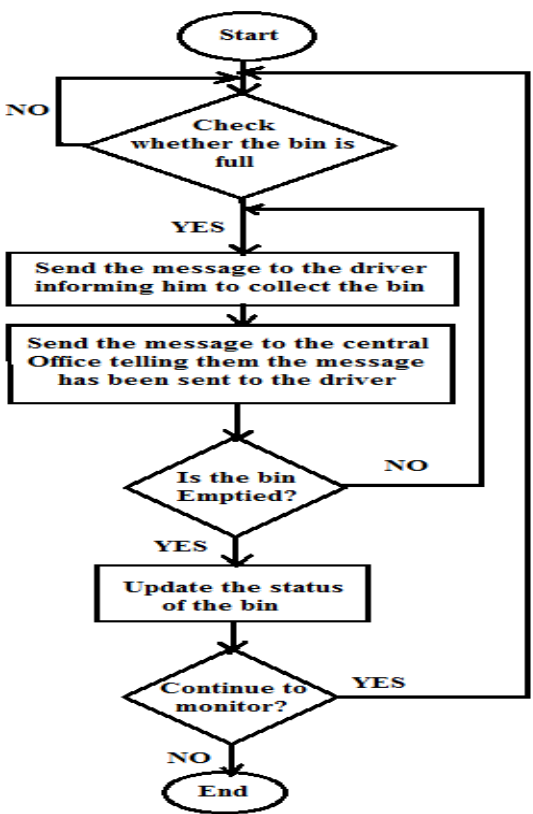

Figure 13 Signal flow graph of the GPS and GSM Based system. Source: Author.

\section{Project Model}

The model of the project is shown in figure 14 .

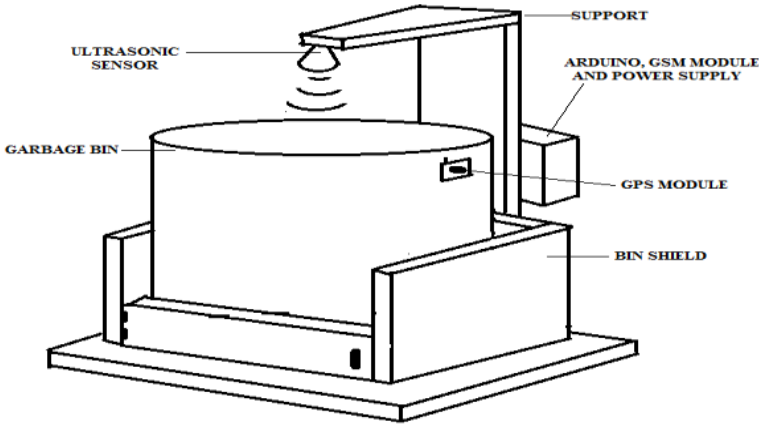

Figure 14 GSM and GPS Based Garbage Management System Model. Source: Author.

It is seen from the model that the GPS Module is attached to the bin. When the bin is ready to be collected, the bin shield is opened and the bin is taken out for disposal of garbage. In case more bins have been collected, when returning them, the collector can place them in any order. That is, the bins can be swapped but the system is able to give the precise location because each bin has its own GPS receiver. The bin shield holds the bin in place.

\section{Schematic Diagram}

The principle operation of the entire project is fully explained using the schematic diagram in figure 15 .

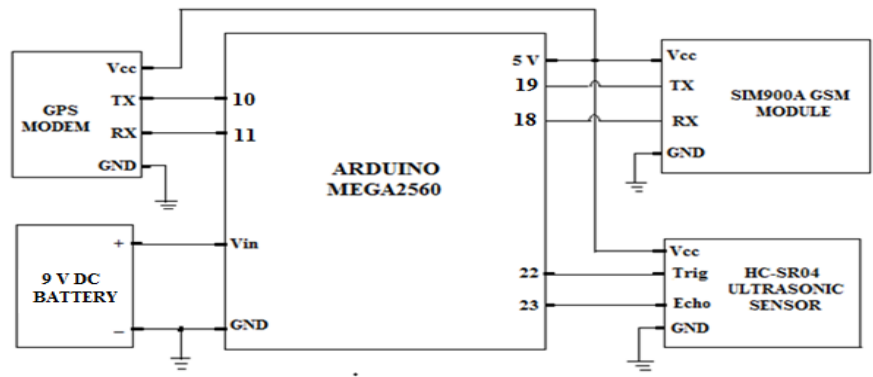

Figure 15 Schematic Diagram of the GPS and GSM Based Garbage Management System for Kitwe City Council. Source: Author.

The diagram can be explained as follows: The 9V DC source powers the Arduino Mega2560 via the Vin pin. Then the Arduino Mega powers the Ultrasonic Sensor, SIM900A GSM Module and the GPS Modem using the $\mathbf{5 V}$ pin. Once the circuit is turned on, the Arduino triggers the sensor through pin 22 so that the sensor transmits pulses to an object, in this case the garbage in the bin. Pulses get reflected and received by the sensor as echoes. The sensor calculates the time taken from when the signal is transmitted to when it is received. It then calculates the distance $D$ in $c m$ using equation (2) as

$$
D=\frac{S * t}{2} * \frac{1}{100}=\frac{340 * t}{2} * \frac{1}{100} \mathrm{~cm}
$$

Where $S$ is the speed of sound in air in meters per second, $t$ is time in seconds taken for the signal to travel from the transmitter to the receiver of the sensor.The division by 100 converts the measured distance from metres into centimetres. This distance is fed to the Arduino through the digital pin 23.

When the measured distance $D$ reaches the threshold value, the Arduino activates the GSM Module into the texting mode. At the same time the GPS Modem is also activated through pin 12. The GPS Modem captures the coordinates of the bin and feeds them to the Arduino through pin 13. These coordinates are transmitted to the GSM Module and combined with the text in GSM Module. This combination is termed as a "notification message". After a delay of about 10 counts, the notification message is sent to the Driver's mobile. The Driver views the message as "The bin is full. Please come and pick it up at:" The Driver uses the coordinates in the message to find the shortest route to the bin ready to be collected. Another message is sent to the Central Office informing them the notification has been sent to the Driver.

Once an empty bin is placed below the sensor the entire process of monitoring the level of the garbage in the bin restarts.

\section{E. Simulation Results}

The system was simulated using Proteus Design Suite 8.0 as shown in figure 16 . 


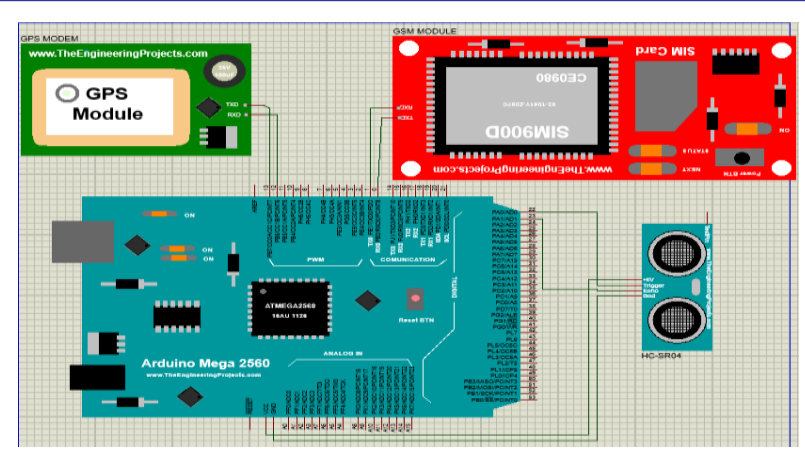

Figure 16 Interfacing the Arduino Mega 2560 with GPS and GSM Module, and HC-SR04 in Proteus 8 Professional. Source: Author

It is quite hard to simulate the GPS and GSM Modules, and the Ultrasonic sensor at once. Thus, in order to see the results, push buttons together with the Liquid Crystal Display (LCD) are used to simulate an instant when the threshold level is reached. Pressing the push button indicates that the bin is full and is ready to be picked. Figures 17 and 18 show the simulation results of two bins at different locations using push buttons and LCD in Proteus.

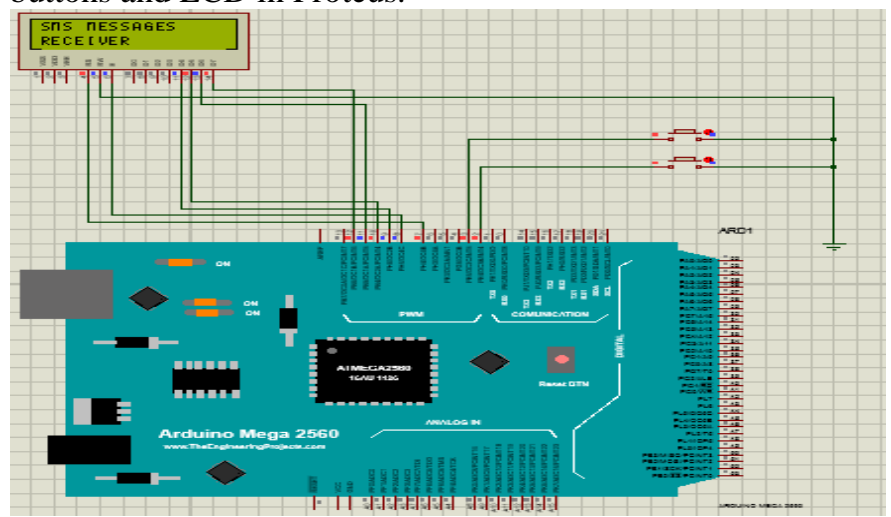

Figure 17 Simulation Results of Empty Bins. Source: Author.
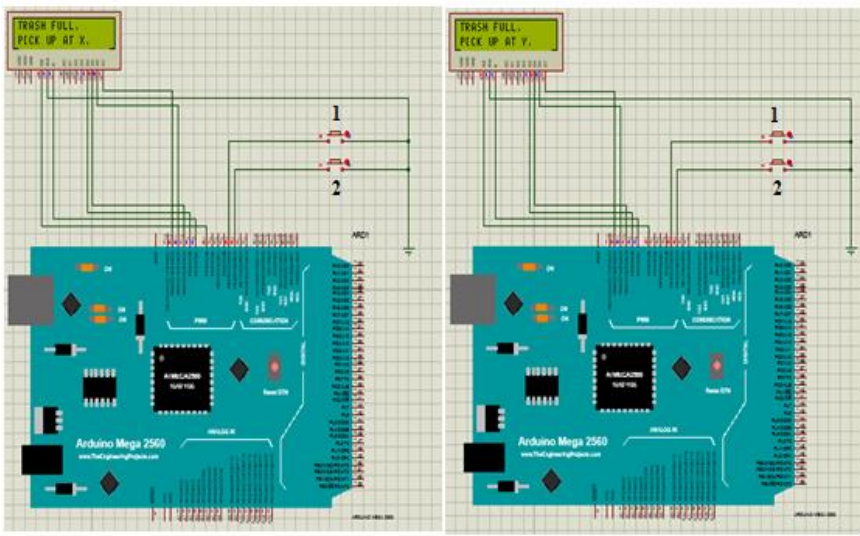

Figure 18 Simulation Results of Full Bins at Different Locations X and Y.

$$
\text { Source: Author. }
$$

Before the bin is full (no button is pressed), the results in figure 17 were shown. The receiver does not receive a notification. But in figure 18 , the receiver gets a notification "TRASH FULL PICK UP AT X OR Y" when

- The bin at location $X$ is full; simulated by pressing push button 1 (lower button)

- The bin at location Y is full; simulated by pressing push button 2 (upper button).

\section{F. System Testing}

Before assembling all the components into one system, individual components were tested. The program code was uploaded to the assembled system. Then the assembled system was tested as shown in figure 19.

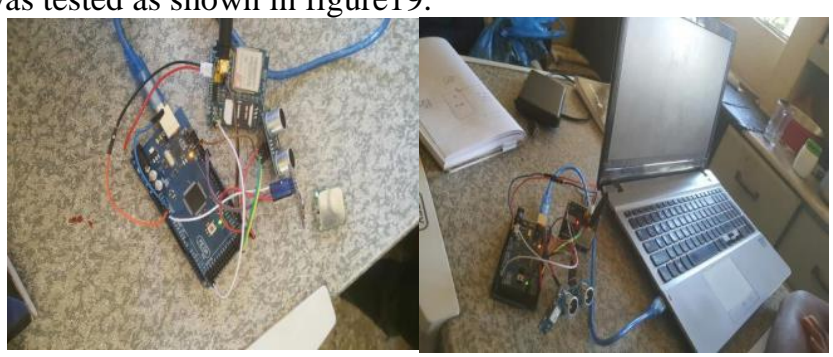

Figure 19 Assembled System Powered by the Computer. Source: Author

\section{G. System Prototype}

After a thorough testing, a physical model was built to represent a manufactured design. The bin shield supports the garbage bin, the main circuit board and the Ultrasonic sensor supporter.Figure 20 shows the system prototype.

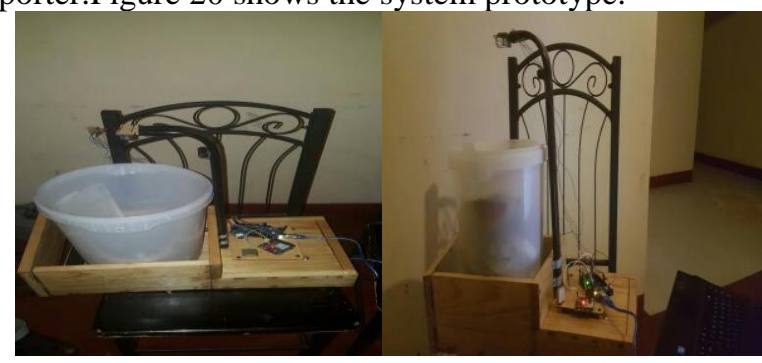

Figure 20 System Prototype. Source: Author

\section{H. Implementation}

To implement the design, the system was powered; the program code was uploaded to Arduino Mega 2560 and the Bin was filled with waste up to the threshold level. The results of the implementation were seen as shown in figure 21 .

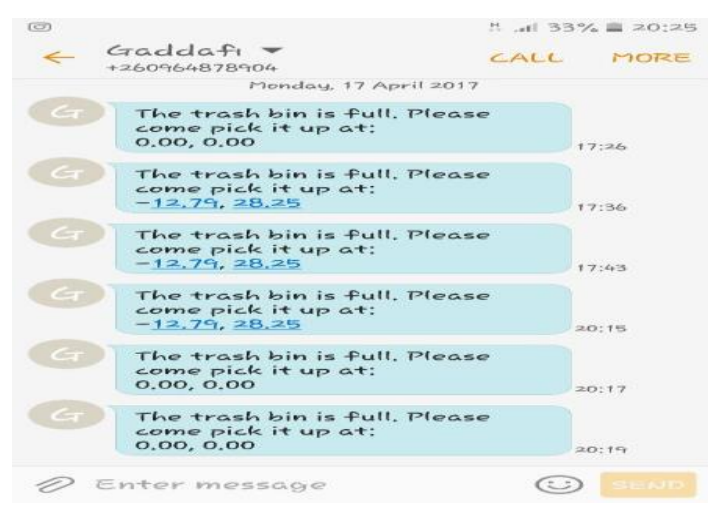

Figure 21 Messages Received by the Driver's Phone when the bin is full. Source: Author

\section{Observations and System Results}

The system is able to monitor the level of the empty bin. The system gives the location of the bin as seen from the coordinates in figure 21 . The message is not sent when the bin is still empty.

As garbage is thrown into the bin, the monitor is able to display the different levels of garbage. When the threshold level is reached, after Ten (10) predetermined counts, the 
message is sent as seen from figure 21. If the bin is not emptied after ninety (90) predetermined counts the same message is resent.

At the time of activation of the system, the GPS Modem takes a longer time to be activated as compared to other system components. After activation, the GPS is able to capture the location while at some instances it is unable to capture the location, hence the difference in coordinates as seen from figure 21 .

\section{CONCLUSION AND FUTURE WORK}

The system is able to monitor the garbage level in the bin, avoid the overflow of garbage by notifying the collector via an SMS and give the precise location. The system provides an efficient and effective way of garbage collection.

The proposed future works:

- Inclusion of the control room will effectively help monitor the garbage level from the Central Office

- Integrating the system with an application based website to have an exact location on the map.

\section{ACKNOWLEDGMENT}

We would like to express our sincere appreciation to the departmental staff who guided us at various stages in the refinement of this project. Special thanks go to the Kitwe City Council Staff and many others that may not have been mentioned by names.

\section{REFERENCES}

[1] University of Tasmania. (2014) dpipwe.tas.gov.au. [Online]. http://dpipwe.tas.gov.au/Documents/Worksheet\%201\%20-

\%20How\%20GPS\%20Works.pdf

[2] (2015) nhdfl.org. [Online]. http://www.nhdfl.org/library/pdf/Forest\%20Protection/Introducti on\%20to\%20Global\%20Positioning\%20System.pdf

[3] International Engineering Consortium. (2015) uky.edu. [Online]. http://www.uky.edu/ jclark/mas355/GSM.PDF

[4] Kanchan Mahajan and Prof.J.S.Chitode, "Waste Bin Monitoring System Using Integrated Technologies," International Journal of Innovative Research in Science, Vol. 3, Issue 7, July 2014, pp. 14953-14956, july 2014.

[5] Ann Mary Thomas, Annu Reji Philip, Tessy Elsa Peter, and Er R P Nishanth, "Dust Bin Monitoring System," International Journal of Advanced Research in Computer and Communication Engineering.Vol. 5, Issue 3, March 2016, pp. 1063-1065, 2016.
[6] H Kasliwal Manasi and B Suryawanshi Smitkumar, "A Novel Approach to Garbage Management Using Internet of Things for Smart Cities," International Journal of Current Trends in Engineering \& Research (IJCTER), e-ISSN 2455-1392 Volume 2 Issue 5, pp. 348 - 353, 2016.

[7] Robert Lexmann. (2016) https://dspace.cvut.cz/bitstream/handle/10467/65602/F2-BP2016-Lexmann-Robert-priloha-4ArduinoMega2560.pdf?sequence $=-1 \&$ isAllowed=y.

[8] Robert Lexmann. (2017, March) mantech.co.za Web site. [Online].

http://www.mantech.co.za/datasheets/products/A000047.pdf

[9] Technology Cytron. (2013, May) Cytron Technologies Sdn. Bhd. Web site. [Online]. https://docs.google.com/document/d/1YyZnNhMYy7rwhAgyL_pfa39RsB-x2qR4vP8saG73rE/edit\#

[10] Kartha Vivek. (2016, March) Electrosome.com. [Online]. https://electrosome.com/hc-sr04-ultrasonic-sensor-raspberrypi/

[11] (2017, March) blogspot.com. [Online]. https://3.bp.blogspot.com/-

bMooX37DyOg/VaU31ZVw28I/AAAAAAAAA40/VhgCezs QA7s/s1600/arduino\%2Bultrasonic\%2Bdistance\%2Bsensor\% 2Blcd\%2B.jpg

[12] Electronics ATRIM. (2014) ATRIM Electronics.in Web site. [Online].

http://extremeelectronics.co.in/datasheets/gsm_shield_sim 900 a.pdf

[13] International GARMIN. (2011, March) static.garmincdn. [Online].

http://static.garmincdn.com/pumac/GPS_18x_Tech_Specs.pdf [14] Robotshop. (2017, March) pixhawk.org Web site. [Online]. http://www.robotshop.com/media/files/images/3dr-gpsmodule-ublox-lea-6-2-ublox-large.jpg

[15] Mohamed Kaleemuddin S, Dinesh Bose, K I Ramachandran Adarsh S, "Performance comparison of Infrared and Ultrasonic sensors for obstacles of different materials in vehicle/ robot navigation applications," IOP Conf. Series: Materials Science and Engineering 149 (2016) 012141 doi:10.1088/1757-899X/149/1/012141, pp. 3-6, 2016.

[16] International Engineering Consortium. (2015) uky.edu Web site. [Online]. http://www.uky.edu/ jclark/mas355/GSM.PDF

[17] Vivek Kartha. (2016, March) electrosome Website. [Online]. https://electrosome.com/hc-sr04-ultrasonic-sensor-raspberrypi/

[18] Datasheet. (2016, February) DatasheetCafe Web site [Online]. http://www.datasheetcafe.com/sim900a-datasheetpdf/ 